\title{
SEASONAL CHANGES IN FOOD QUALITY: A PROXIMATE CUE FOR REPRODUCTIVE TIMING IN MARINE IGUANAS
}

\author{
Dustin R. Rubenstein ${ }^{1,3}$ AND Martin WikeLSKI ${ }^{2}$ \\ ${ }^{1}$ Cornell University, Department of Neurobiology and Behavior, Seeley G. Mudd Hall, Ithaca, New York 14853 USA \\ ${ }^{2}$ Princeton University, Department of Ecology and Evolutionary Biology, Guyot Hall 303, \\ Princeton, New Jersey 08540 USA
}

\begin{abstract}
We investigated the proximate environmental cues that influence the timing of reproduction in the seasonally and synchronously breeding Galápagos marine iguana (Amblyrhynchus cristatus). Marine iguana foraging patterns are closely linked to the tidal cycle, and they feed exclusively on macroalgae. The Galápagos Islands are characterized by seasonal currents that impact water temperature and ultimately algal abundance, which is known to affect iguana body condition and survival. In our study, marine iguanas preferred Gelidium sp., which had the highest nutritional quality (nitrogen content, carbon content, and $\mathrm{C}: \mathrm{N}$ ratio) of the three species of macroalgae on which they feed. Nutritional quality in Gelidium changed predictably with increasing sea surface temperature, peaking around the median iguana copulation date. Similarly, foraging behavior changed around the time copulations began. To test if consistent relationships existed among food quality, water temperature, and breeding life history, we used seven years of data from this population and found that breeding occurred earlier in years when the mean December sea surface temperature was warmer. Although iguanas might cue directly on changes in sea surface temperature, given the frequency and intensity of El Niño events in the Galápagos, this hypothesis is unlikely. Rather, our results suggest that marine iguanas may use subtle changes in food quality (particularly energy content) associated with seasonal, but annually variable, changes in water temperature as a cue to initiate breeding. The excess available energy may be used to withstand the costly breeding period, as well as to provision yolk to improve hatchling growth and survival.
\end{abstract}

Key words: Amblyrynchus cristatus; C:N ratio; carbon content; food quality; Galápagos marine iguanas; nitrogen content.

\section{INTRODUCTION}

When an individual chooses to breed has important fitness consequences. Both the age of first reproduction (Pianka 1976), as well as the timing-month or season-of reproduction (Kennish 1997), can influence lifetime reproductive success. Most animals have discrete periods of breeding and nonbreeding that are integrated and regulated by environmental cues (Wingfield et al. 1992, 1993). By determining the proximate cues used to adjust the timing of reproduction, we can make inferences about the selection pressures that may have influenced the evolution of reproductive cycles and ultimately maximized lifetime fitness.

Food availability influences the timing of reproduction in many species of birds (Perrins 1970, Drent and Daan 1980), reptiles (Rand and Greene 1982, Wiewandt 1982, van Marken Lichtenbelt and Albers 1993), mammals (Bodenheimer and Sulman 1946, Talbot and Talbot 1963, Bunnell 1980), fish (Clifton 1995, Caceres et al. 1994), and invertebrates (Kennish 1997). A shortage of food prior to breeding can directly influence a female's ability to conceive (Bomford 1987, Cook et

Manuscript received 12 June 2002; revised 12 February 2003; accepted 3 March 2003. Corresponding Editor: B. Sinervo.

${ }^{3}$ E-mail: drr24@cornell.edu al. 2001), or indirectly affect offspring survival depending on how the female apportions nutrients (i.e., energy) during fetal development in mammals (Thorne et al. 1976) or vitellogenesis in birds and reptiles (Congdon 1989). Alternatively, a shortage of food after parturition or hatching can directly affect offspring survival (Lack 1947, Cote and Festa-Bianchet 2001). Species that are income breeders, or do not use stored reserves to breed, should be more sensitive to food availability immediately before and during breeding, whereas food availability after parturition or hatching should be more critical for species that are capital breeders and use stored reserves to breed. Thus, if food is seasonally limiting for a species, natural selection should (1) act to synchronize breeding (Rutberg 1987), and (2) favor breeding times when food is most available for the parents directly preceding breeding (for income breeders) or for the offspring directly following breeding (for capital breeders).

In the course of a long-term study of the Galápagos marine iguana (Amblyrhynchus cristatus), we became interested in the proximate environmental cues that influence the timing of reproduction in this endemic reptile. Marine iguanas breed seasonally and synchronously once a year, but the timing of reproduction varies by a couple of months among the different pop- 
ulations or subspecies inhabiting each island (Wikelski and Trillmich 1994). Although considered to be rigid and predictable (Boersma 1983), the breeding period can often vary by a few weeks from year to year on a given island (M. Wikelski, personal observations). Hatchlings emerge approximately four months after breeding (Eibl-Eibesfeldt 1984) and, although they occasionally feed on algae in the upper intertidal zone (Dawson et al. 1977, Boersma 1983), they mainly eat adult feces (presumably to obtain gut microbes essential for digestion as in green iguanas; Troyer 1982, Wikelski et al. 2002) for approximately the first two months (Boersma 1983; M. Wikelski, personal observations). Marine iguanas are unique among iguanines in that they forage almost exclusively on marine macroalgae in the intertidal zone or by diving subtidally (Darwin 1883, Trillmich and Trillmich 1986).

Food availability has been an important selection force in the evolution of body size in marine iguanas (Wikelski et al. 1997, Wikelski and Wrege 2000), and may have been equally important in the evolution of their breeding life history (Boersma 1983, Laurie 1990). Marine iguanas are known to be food limited (Laurie 1989), and body condition and survival are directly impacted by food availability (Laurie 1989, Laurie and Brown 1990b, Romero and Wikelski 2001). These environmentally induced changes in body condition caused by changes in food availability influence breeding life history parameters such as clutch size, clutch weight, frequency of breeding, and age of first reproduction (Laurie 1990). Boersma (1983) suggested that breeding in marine iguanas occurs when food availability is highest: around the time of the annual lowest low tide when the greatest amount of intertidal algae is exposed. However, strong seasonal variation in algal abundance (Houvenaghel 1978, Laurie 1989), and presumably nutritional quality, may also strongly influence food availability for marine iguanas and better explain why the timing of reproduction varies from year to year on a given island, as well as among islands. The waters around the Galápagos Islands are characterized by highly seasonal currents that cause marked changes in water temperature, nutrient levels, and water movement patterns (Pak and Zanveld 1973, Feldman 1986, Fahrbach et al. 1991) that affect algal abundance and growth (Houvenaghel 1978, Wikelski et al. 1997). Thus, we hypothesize that marine iguanas may use changes in food resources, such as food quality (i.e., algal nutritional quality) or food quantity (i.e., algal abundance), associated with annual changes in water temperature, as a cue to initiate reproduction.

In this study, we determined whether changes in algal quality and/or quantity associated with seasonal changes in water temperature affected the timing of reproduction. We studied a single population on the island of Santa Fé for one breeding season and looked for changes in food quality, food quantity, and foraging behavior that coincided with the timing of reproduction and correlated with changes in sea surface temperature. We then used data from six additional breeding seasons from the same population to confirm the relationship between sea surface temperature (as a correlate of food availability) and the timing of reproduction in the Galápagos marine iguana (see Plate 1).

\section{Methods}

\section{Study site and environmental measures}

Marine iguanas were continuously monitored on Santa Fé island $\left(90^{\circ} 02^{\prime} \mathrm{W}, 0^{\circ} 50^{\prime} \mathrm{S}\right)$, one of the central islands in the Galápagos, from 11 November 1999 until 11 January 2000 (during a La Niña event with belowaverage water temperatures). Our study site at Miedo Beach consisted of a steep, rocky beach coastline, $\sim 75$ $\mathrm{m}$ long, with intertidal zone flats abundant with two species of red macrophytic algae, Centroseras sp. and Gelidium sp., and one species of green algae, Ulva sp. (Wikelski et al. 1993). Although marine iguanas feed on all three species (Wikelski et al. 1993, Wikelski and Wrege 2000), the preferred diet on Santa Fé was red algae, particularly Gelidium (Wikelski et al. 1993). Times for high and low tide were obtained for the neighboring island of San Cristobal at Bahia de Agua Dulce $\left(89^{\circ} 37^{\prime} \mathrm{W}, 0^{\circ} 54^{\prime} \mathrm{S}\right)$. Sea surface temperatures were recorded to the nearest $0.2^{\circ} \mathrm{C}$ using a glass thermometer.

\section{Algal sampling}

We sampled the three dominant species of algae five times from 11 November 1999 to 1 February 2000 in four areas in the lower intertidal zone that were visually distinct in their algal composition. We used a standard tape measure to estimate the intertidal depth of each area, which was calculated as the vertical distance from the high tide line to the nearest $1 \mathrm{~cm}$ (increasing intertidal depth is defined as moving from the high tide line to the low tide line, i.e., closer to the water). Three samples of each species from each area were collected within $3 \mathrm{~m}$ of a transect line that ran perpendicular to the high tide line and then cleaned of all epiphytic algae and microorganisms. Changes in algal blade length are the best estimate for changes in algal abundance, or quantity, because algal abundance does not change until its blade length is less than $1 \mathrm{~mm}$ (Wikelski et al. 1997). Algal length was measured to the nearest $1 \mathrm{~mm}$ using a ruler.

\section{Nutrient analyses}

We assessed food quality by measuring carbon content $(\% \mathrm{C})$, nitrogen content $(\% \mathrm{~N})$, and the $\mathrm{C}: \mathrm{N}$ ratio. In macroalgae, carbon content is highly correlated with energy content (Kaehler and Kennish 1996, Rico and Fernandez 1996) and nitrogen content with protein content (Rico and Fernandez 1996). The ratio of C:N has been used as a more general estimate of food quality (Niell 1976, Sterner and Hessen 1994). Samples were 


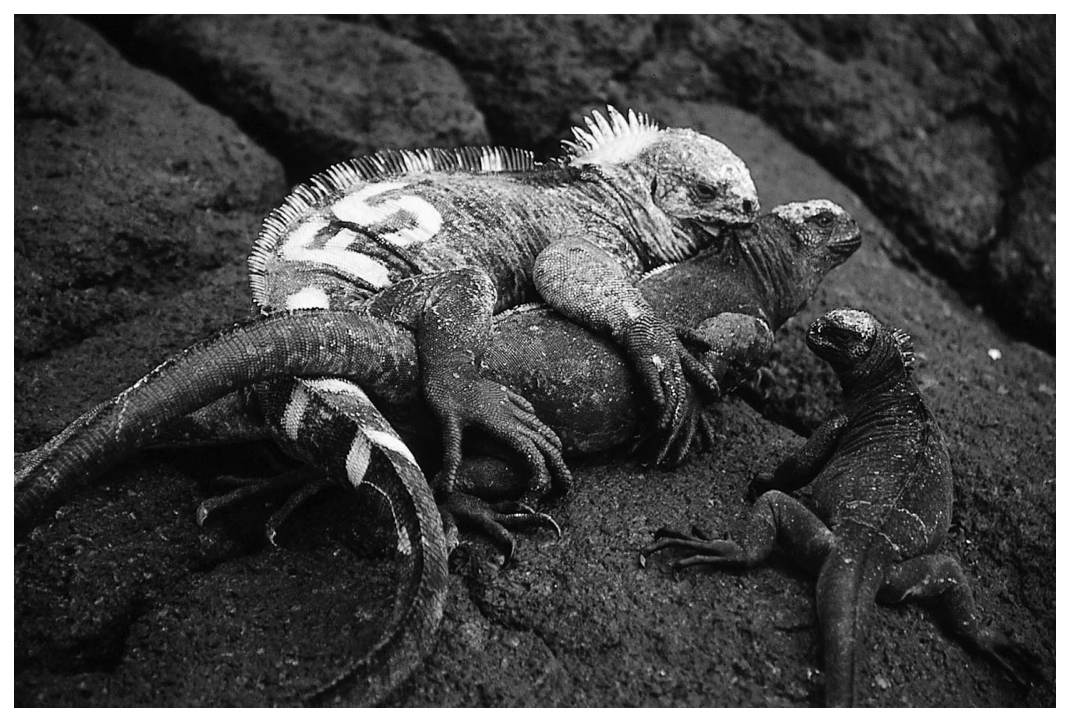

Plate 1. Territorial marine iguana in the midst of a successful copulation. Photo credit: D. R. Rubenstein.

dried at $60^{\circ} \mathrm{C}$ for $48 \mathrm{~h}$ and freeze-dried for another 48 h until dry mass was stable. Homogenized samples of 0.9-1.0 mg were combusted using a Finnegan Carlo Erba Automatic Combustion System (CHN analyzer; Fisons Instruments, Milan, Italy) and analyzed on a Finnegan MAT 252 gas source mass spectrometer (Finnegan, Bremen, Germany; accuracy for $\mathrm{C}, \pm 0.87 \%$ and for $\mathrm{N}, \pm 0.19 \%)$.

\section{Behavioral observations}

We marked 119 marine iguanas (101 males and 18 females) of all sizes with temporary paint numbers, which do not affect the behavior of the animals (Partecke et al. 2002; M. Wikelski and D. Audet, unpublished data), on their flanks for identification (see Plate 1). Behavioral observations were made continuously from 0730 hours until 1730 hours from 14 November 1999 until 9 January 2000. We recorded all successful copulations (those that lasted longer than 2 min; Wikelski and Bäurle 1996). Since females tend to copulate only once per season (Wikelski et al. 1996), we estimated the timing of reproduction as the median copulation date because it represents the time when most of the animals in the population were breeding. We had four observers continuously monitoring the study area, so we are confident that we were able to see most of the copulations and that certain animals were not biased with respect to observer time. Foraging observations were made by the same observer from 11 November 1999 until 9 January 2000 and spanned three complete tidal cycles. For every foraging bout made by each marked animal, we recorded (1) the start time (when the animal entered the intertidal zone or water to feed), and/or (2) stop time (when it left the intertidal zone or climbed to a high point and stopped feeding for more than $2 \mathrm{~min}$ ), and (3) whether it foraged intertidally or subtidally (Wikelski and Trillmich 1994).

\section{Data analysis}

We tested for differences in nutritional quality (nitrogen content, carbon content, and $\mathrm{C}: \mathrm{N}$ ratio) among the three species of macroalgae using analysis of variance models. We included species type, intertidal area, sampling period, and all possible interaction terms in the models, but we only report the statistics for species type. We used independent contrasts on the least square means to test for significant differences among species pairs. A correlation between sea surface temperature and date was used to confirm the expected seasonal changes in water temperature. Multiple regression models were used to determine the effects of sea surface temperature and intertidal depth on (1) food quality (carbon content, nitrogen content, $\mathrm{C}: \mathrm{N}$ ratio) and (2) food quantity (algal blade length). Linear and quadratic terms were used in all of the models. Date was not included as an independent variable because it correlated strongly $(r=0.97)$ with sea surface temperature.

We used regression analyses to examine the relationship between mean intertidal foraging start time and the time of low tide, as well as between mean subtidal foraging start time and the time of high tide. Only days when $\geq 10$ foraging start times were observed were used in the analysis. A chi-square goodness of fit test was used to determine if males foraged subtidally more often than females, and an analysis of covariance was used to determine if the length of intertidal foraging bouts differed between males and females over the course of the breeding season. Since foraging bout length did not differ between the sexes, we combined observations and used regression analyses and a $t$ test to examine the relationship between mean foraging bout length and date during (1) the period before the first copulation occurred and (2) the period after the first copulation occurred. 
We used a multiple regression model to determine if the mean sea surface temperature for the month of December, the date of the lowest December low tide, and their interaction terms were related to the median copulation date. Only those independent variables that were significant at $P<0.05$ were used in the final model and reported in the results. We calculated a $90 \%$ confidence interval around the relationship between mean December sea surface temperature and median copulation date to determine if values from two anomalous years with strong El Niño events fell within the interval.

\section{RESUlts \\ Food quality}

Carbon content was positively correlated with nitrogen content in each of the three algae species (correlations: Gelidium, $F_{1,57}=438.13, r=0.94, P<0.0001$; Centroseras, $F_{1,58}=197.34, r=0.88, P<0.0001$; Ulva, $\left.F_{1,58}=100.16, r=0.79, P<0.0001\right)$. However, there were significant differences in carbon content, nitrogen content, and $\mathrm{C}: \mathrm{N}$ ratio among the three species (ANOVA, only statistics for species type are reported: carbon content, $F_{2,119}=198.90, P<0.0001$; nitrogen content, $F_{2,119}=101.94, P<0.0001 ; \mathrm{C}: \mathrm{N}, F_{2,119}=$ 262.31, $P<0.0001$; Fig. 1). Since (1) our foraging observations suggested that marine iguanas fed mainly on Gelidium, and (2) an examination of 625 freshly laid feces samples indicated that they foraged exclusively on red algae and primarily on Gelidium (Ulva was present in 0 of 625 samples), we only present data for Gelidium in the rest of our analyses.

\section{Seasonal changes in food quality and quantity}

Sea surface temperature increased linearly over the course of the season, from $17.5^{\circ} \mathrm{C}$ on 11 November 1999 to $25^{\circ} \mathrm{C}$ on 1 February 2000 (correlation $F_{1,3}=$ 41.69, $r=0.97, P=0.0075)$. This $7.5^{\circ} \mathrm{C}$ rise in sea surface temperature is greater than for an average year (i.e., no El Niño or La Niña event) on Santa Fé when it only rises approximately $4.5^{\circ} \mathrm{C}$ (Wikelski et al. 1997). Furthermore, because of the La Niña event, the mean December sea surface temperature was considerably colder $\left(21.3^{\circ} \mathrm{C}\right)$ than in December of most other years $\left(23^{\circ} \mathrm{C}\right.$; mean over seven years).

Carbon content in Gelidium increased with intertidal depth and showed a significant quadratic relationship with increasing sea surface temperature (multiple regression: intertidal depth, $F_{1,54}=8.78, P=0.0045$; intertidal depth ${ }^{2}, F_{1,54}=7.34, P=0.0090$; sea surface temperature, $F_{1,54}=10.36, P=0.0022$; sea surface temperature ${ }^{2}, F_{1,54}=9.55, P=0.0032$; Fig. 2). Nitrogen content increased with intertidal depth, but only showed a nearly significant relationship with increasing sea surface temperature (multiple regression: intertidal depth, $F_{1,54}=10.72, P=0.0019$; intertidal depth ${ }^{2}, F_{1,54}$ $=9.23, P=0.0037$; sea surface temperature, $F_{1,54}=$
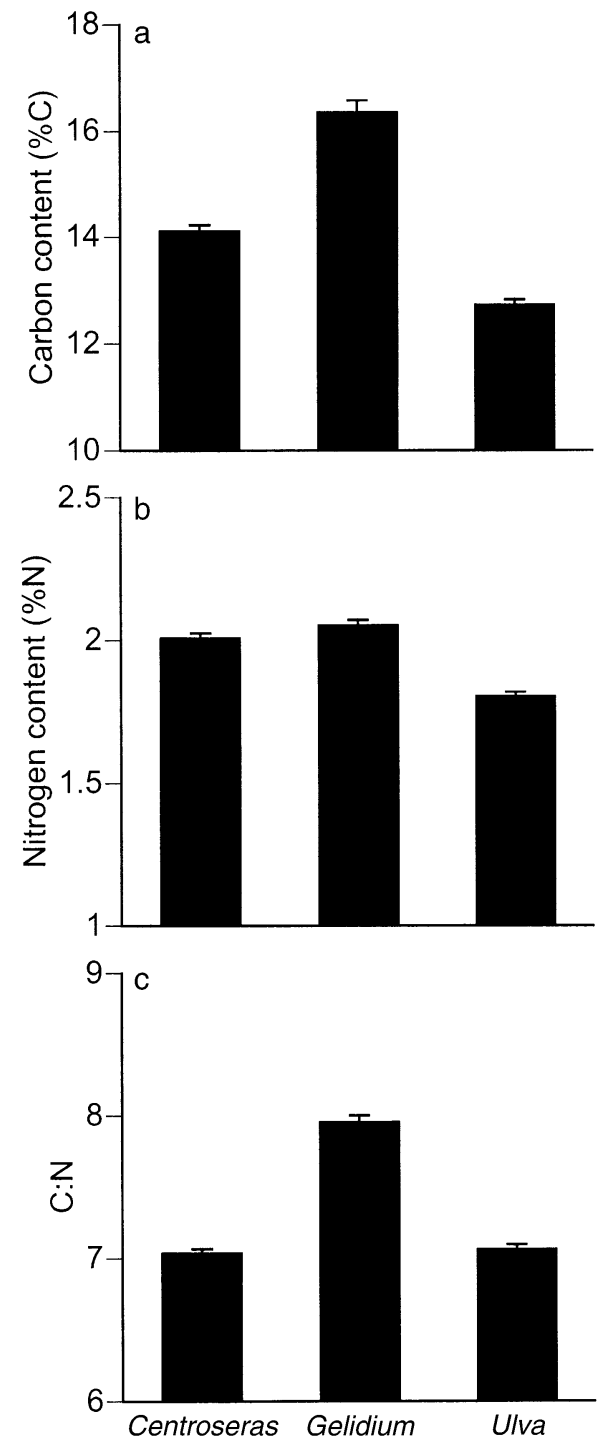

FIG. 1. (a) Carbon content, (b) nitrogen content, and (c) $\mathrm{C}: \mathrm{N}$ ratios differed among the three species of macroalgae. Bars represent mean values $+1 \mathrm{SE}$ for each species pooled for the four lower intertidal zones and five sampling periods. Gelidium contained significantly more carbon and nitrogen than Centroseras (14\% and 3\% higher carbon and nitrogen, respectively; all $P<0.01)$ and Ulva $(22 \%$ and $12 \%$ higher carbon and nitrogen, respectively; all $P<0.0001)$. The C:N ratio in Gelidium was $12 \%$ higher than Centroseras $(P<$ $0.0001)$ and $11 \%$ higher than Ulva $(P<0.0001)$.

3.72, $P=0.059$; sea surface temperature ${ }^{2}, F_{1,54}=3.07$, $P=0.086$; Fig. 2). The $\mathrm{C}: \mathrm{N}$ ratio also tended to increase with intertidal depth, and showed a significant quadratic relationship with increasing sea surface temperature (multiple regression: intertidal depth, $F_{1,54}=$ 3.03, $P=0.088$; intertidal depth ${ }^{2}, F_{1,54}=2.28, P=$ 0.14 ; sea surface temperature, $F_{1,54}=19.530, P<$ 0.0001 ; sea surface temperature ${ }^{2}, F_{1,54}=19.29, P<$ 0.0001 ; Fig. 2). We estimated the optimal growing temperature (reflected in terms of carbon production, i.e., 

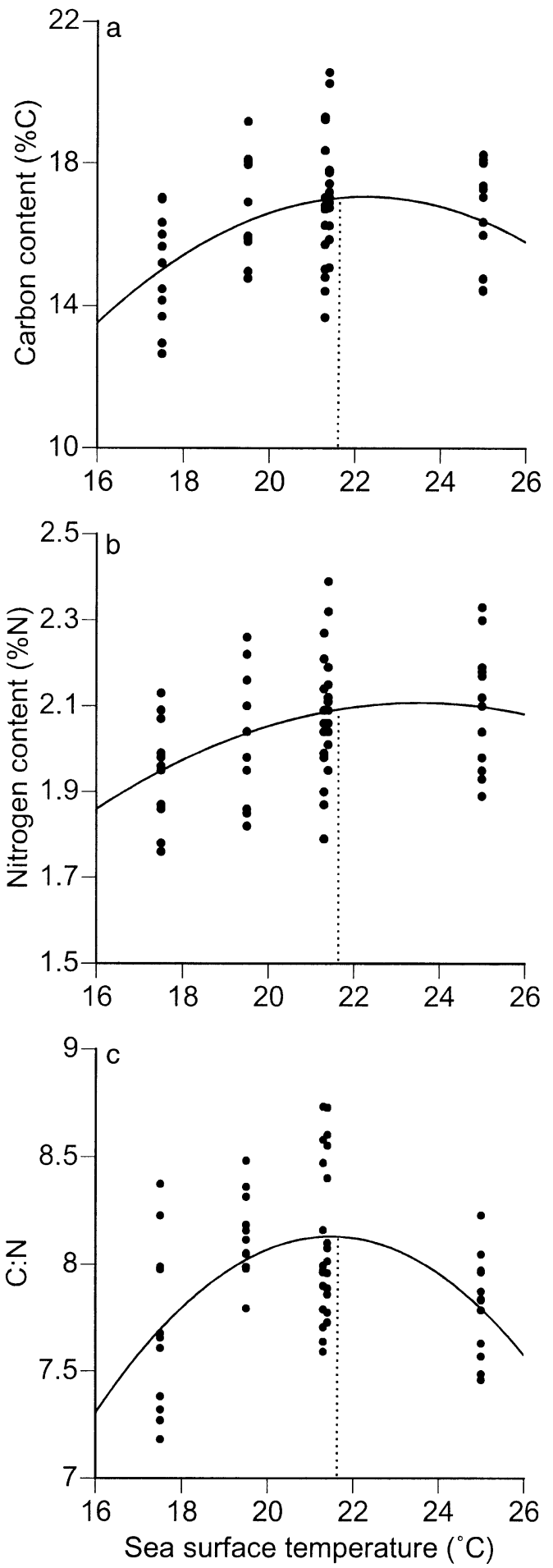

FIG. 2. (a) Carbon content, (b) nitrogen content, and (c) $\mathrm{C}: \mathrm{N}$ ratios in Gelidium changed predictably over the course of the breeding season with increasing sea surface temperature. The approximate sea surface temperature $\left(21.6^{\circ} \mathrm{C}\right)$ on the median copulation date is depicted by the dotted line. The nitrogen content continued to increase during the breeding season, while the carbon content and $\mathrm{C}: \mathrm{N}$ ratio reached a peak and then began to decline.

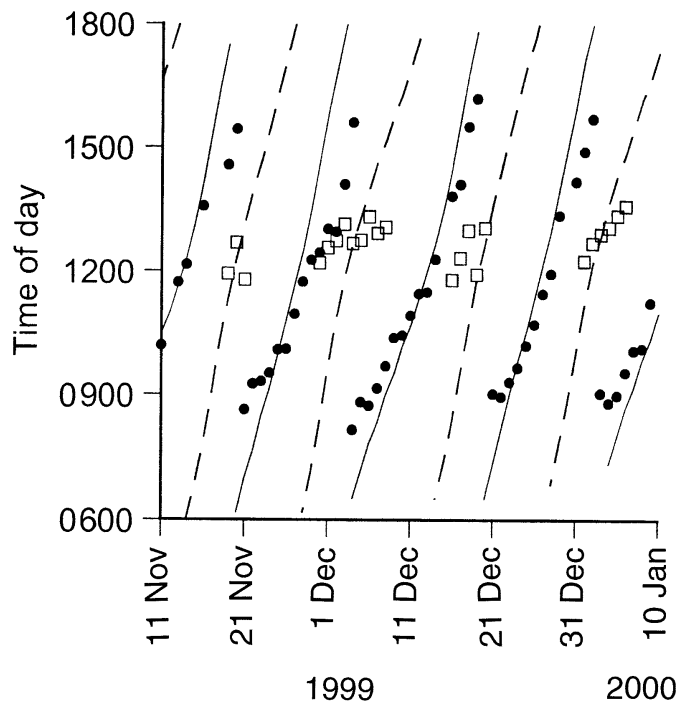

FIG. 3. Foraging behavior coincided with the tidal cycle. Mean intertidal foraging start times $(\bullet)$ and mean subtidal foraging start times ( $\square$ ) are shown. Low tide (solid line) and high tide (dashed line) cycles are also depicted. We observed 4160 bouts of intertidal foraging and 1072 bouts of subtidal foraging over the course of 58 days. Females foraged subtidally $<1 \%$ of the time ( 5 of 718 total foraging observations), while males foraged subtidally $24 \%$ of the time (1067 of 4514 total foraging observations; chi-square test, $\chi^{2}=309.67$, df $=1, P<0.0001$ ).

carbon content and C:N ratio; sensu Lapointe and Ryther 1979, Macler 1986, Fredriksen and Rueness 1989, Rico and Fernandez 1996) for Gelidium by taking the derivatives of the quadratic relationships to estimate the peaks of the curves (carbon content $d x / d t=22.3$; $\mathrm{C}: \mathrm{N} d x / d t=21.5$; Fig. 2). Since sea surface temperature was highly correlated with date, we calculated the dates at which nutritional quality peaked in Gelidium as 7 January 2000 and 31 December 1999 (carbon content and $\mathrm{C}: \mathrm{N}$ ratio, respectively).

Algal quantity (i.e., blade length) did not change over the course of the breeding season as sea surface temperature increased, but it did increase with intertidal depth (multiple regression: intertidal depth, $F_{1,54}=$ 11.81, $P=0.0011$; intertidal depth ${ }^{2}, F_{1,54}=7.86, P=$ 0.007; sea surface temperature, $F_{1,54}=1.53, P=0.22$; sea surface temperature $\left.{ }^{2}, F_{1,54}=1.34, P=0.25\right)$. As the season progressed, the red algae, Gelidium and Centroseras, became bleached and disappeared from the upper intertidal zone, but little bleaching occurred in the lower intertidal zone (where all of our samples were collected).

\section{Foraging behavior}

Iguana foraging behavior was closely tied to the tidal cycle (Fig. 3). Time of mean daily intertidal foraging bout was related to the time of low tide (regression, $F_{1,51}=796.48, r^{2}=0.94, P<0.0001$ ), and time of mean daily subtidal foraging bout was related to the 


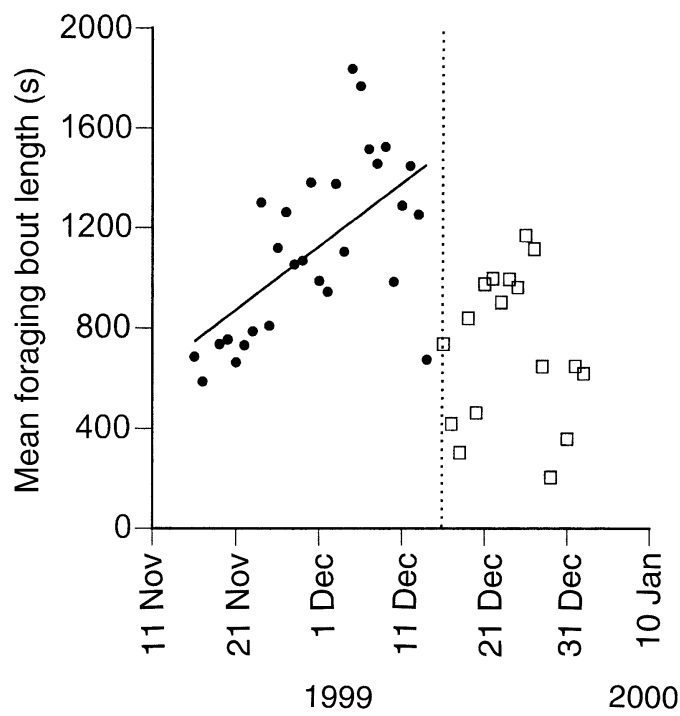

FIG. 4. The mean foraging bout length varied over the course of the breeding season. The day the first copulation occurred (16 December 1999) is depicted by the dotted line. In the beginning of the breeding season (before the first copulation occurred) the mean foraging bout length increased linearly as the season progressed. However, after copulations began, this linear relationship disappeared.

time of high tide (regression, $F_{1,19}=13.84, r^{2}=0.42$, $P=0.0015)$. We found no difference between males and females in the mean length of intertidal foraging bout (ANCOVA: sex, $F_{1,90}=3.43, P=0.067$; date, $F_{1,90}=12.07, P=0.0008$; interaction, $F_{1,90}=2.82, P$ $=0.97)$. Marine iguanas increased their mean foraging bout length up until the day the first copulation occurred (regression, $F_{1,26}=14.84, r^{2}=0.36, P=0.0007$; Fig. 4), at which time the relationship disappeared for the remaining portion of the breeding season (regression, $F_{1,15}=0.032, r^{2}=0.002, P=0.86$; Fig. 4). Moreover, the mean foraging bout length was greater during the period before the first copulation occurred than the period after copulations began $\left(t_{43}=3.77, P\right.$ $=0.0005)$.

\section{Copulation date, sea surface temperature, and low tide}

Using the regression equation from the relationship between date and sea surface temperature, we reliably estimated the sea surface temperature as $21.6^{\circ} \mathrm{C}$ on the median copulation date (Fig. 5). We also examined data collected during the breeding season on Santa Fé from six additional years to look for a relationship between sea surface temperature, low tide, and copulation date. Since marine iguanas on Santa Fé always breed during December, we used the mean December sea surface temperature and the date of the lowest low tide of the month in our model. There was no effect of low tide date, but we did find that as the mean sea surface temperature for the month of December increased, the me-

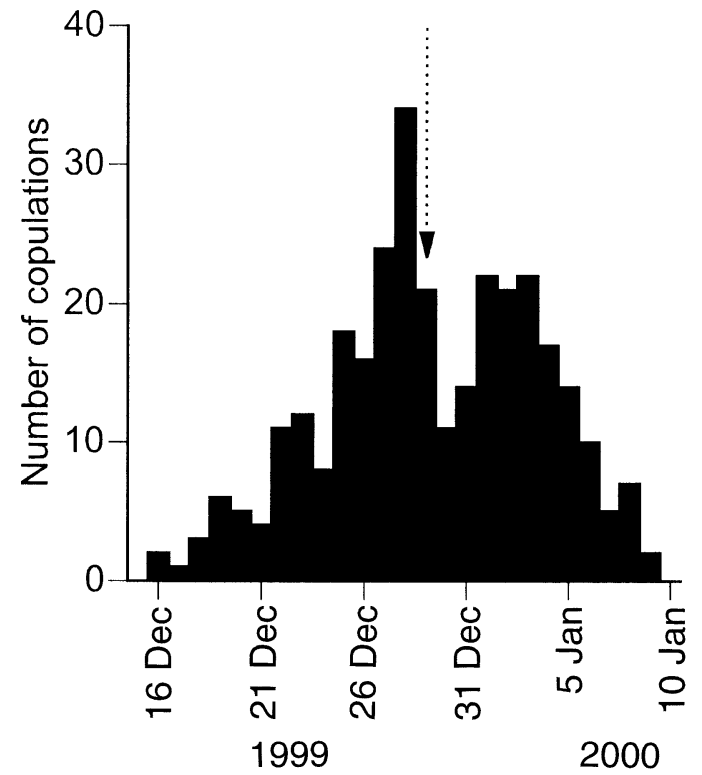

FIG. 5. Copulations $(n=310)$ observed from 16 December 1999 to 9 January 2000. The arrow depicts the median copulation date (29 December 1999). The median copulation date from seven years of observations was 23 December ( \pm 4 days; mean $\pm 1 \mathrm{SD}$ ). The dip in copulations around 31 December 1999 was caused by extremely rough ocean conditions highlighted by strong waves that caused most males to temporarily abandon their territories and retreat to higher ground for a few days.

dian copulation date occurred earlier (regression, $F_{1,5}$ = 52.95, $r^{2}=0.91, P=0.0008$; Fig. 6).

To help determine if iguanas might directly use sea surface temperature or food quality as a cue to initiate breeding, we used limited data from this Santa Fé population from two years (1982 and 1997) that experienced strong El Niño events, and thus extreme fluc-

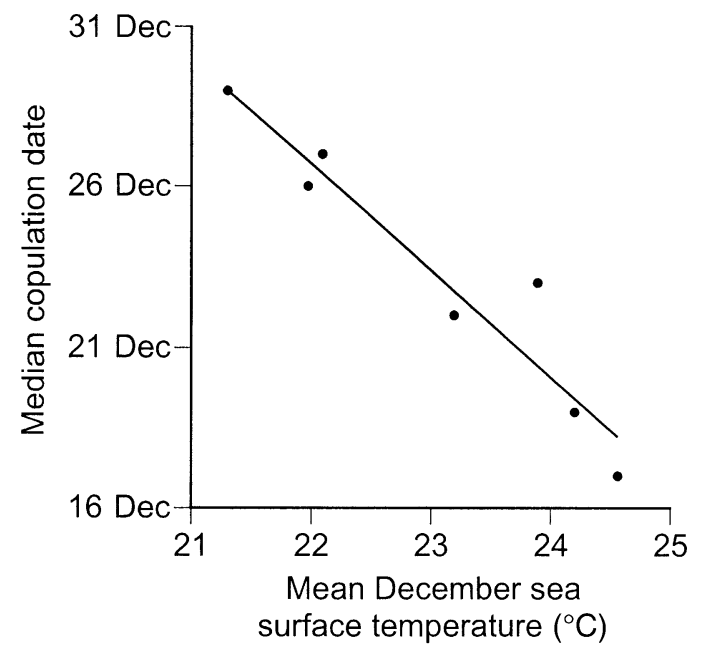

FIG. 6. The median copulation date vs. mean December sea surface temperature. The breeding season began earlier in years when the water temperature was warmer. 
tuations in water temperature. In 1982, the few animals that tried to reproduce did so around 15 December (median copulation date; W. A. Laurie, unpublished data) when the mean December sea surface temperature was $27.2^{\circ} \mathrm{C}$. In 1997 , the median copulation date was roughly around 17 December, and the mean December sea surface temperature was $28.3^{\circ} \mathrm{C}$ (M. Wikelski, unpublished data). These values fall outside a $90 \%$ confidence interval around the relationship between December sea surface temperature and copulation date as determined from the seven non-El Niño years (Fig. 6), indicating that during El Niño years, the timing of reproduction is not related to sea surface temperature. Moreover, during the 1997 El Niño year, algal coverage was still high in December even though it normally declines when water temperatures get that warm (M. Wikelski, personal observations). We did not have corresponding observations from the 1982 El Niño event.

\section{Discussion}

\section{Seasonal patterns of food quality and quantity}

Marine iguanas preferred Gelidium, which had greater carbon content, nitrogen content, and $\mathrm{C}: \mathrm{N}$ ratio than Centroseras or Ulva, and foraged primarily in the lower intertidal zone where Gelidium abundance and quality was highest. These results are consistent with Wikelski et al. (1993) who found red algae, a combination of Centroseras and Gelidium, to be higher than green algae in both protein (nitrogen content) and energy (carbon content). In general, both carbon and nitrogen constitute only a small proportion of marine macroalgae, sometimes as little as $15 \%$ of the combined dry mass (Niell 1976). Wikelski and Wrege (2000) found that a mixture of the red and green macroalgae contained $3 \%$ nitrogen and $32 \%$ carbon, and many other studies have found similarly low values for other species of red and green algae (Niell 1976, Hanisak 1979, Duarte 1992, Rico and Fernandez 1996). Gelidiales, however, are known to be one of the more energy rich species of macroalgae (Patterson 1977). C:N ratios in macroalgae have been reported to vary from 5 to 40 (Niell 1976, Hanisak 1979), but critical values lie between 10 and 15 (Fredriksen and Rueness 1989). Lower values indicate a period of active growth and nitrogen storage (Niell 1976), while higher values indicate nitrogen limitation (Lapointe and Ryther 1979). Our results indicate that while nitrogen content was generally low, it may not have been limiting for any of the three algae species. Thus, significant differences in energy content, reflected in the carbon content and $\mathrm{C}: \mathrm{N}$ ratio, among the three species of macroalgae might explain why Gelidium was preferred by marine iguanas.

Although the quantity (algal abundance) of Gelidium did not change over the course of the breeding season, the nutritional quality varied predictably. While nitrogen content continued to increase throughout the season, carbon content and the $\mathrm{C}: \mathrm{N}$ ratio peaked and then began to decline. This is consistent with most other species of macroalgae, which show seasonal changes in nutritional quality reflected as periodic patterns in carbon and nitrogen content that tend to increase or decrease at roughly the same time (e.g., Black and Dewar 1949, Hanisak 1979, Rico and Fernandez 1996, Kennish 1997).

Both macroalgae abundance, a measure of food quantity, and growth, a measure of food quality, depend on a complex interaction among factors such as irradiance, water temperature, nutrients, and water movement (Lapointe and Ryther 1979, Oliger and Santelices 1981, Macler 1986, 1988, Santelices 1991). Gelidiale growth, however, may be most impacted by sea surface temperature (Hernandez-Guerrero et al. 2000). Although the sea surface temperature increased linearly over the course of the breeding season, the Gelidium quality (best expressed as the C:N ratio; Niell 1976, Sterner and Hessen 1994) only increased until the sea surface temperature reached approximately $21.6^{\circ} \mathrm{C}$. This peak corresponds with the optimal temperature growth range (i.e., carbon production) in tropical Gelidiales (17-25 ${ }^{\circ}$; Fralick et al. 1990) and in two species of lower intertidal Chilean Gelidiales $\left(20-21^{\circ} \mathrm{C}\right.$; Oliger and Santelices 1981).

\section{Reproductive timing, food quality, and sea surface temperature}

Although marine iguana foraging was closely tied to the tidal cycle, foraging patterns changed over the course of the breeding season. Mean foraging bout length increased linearly up until the day the first copulation occurred, but this relationship disappeared in the period after copulations began. This also coincided with the time when food quality began to decline, and suggests that part of this change in foraging behavior could have been due to the change in food quality. Alternatively, it could simply reflect a trade-off in the amount of time spent foraging and on territories once breeding began.

The median copulation date corresponded with the peak in Gelidium nutritional quality, suggesting a relationship between algal quality and the timing of reproduction. If marine iguanas alter their foraging behavior and vary the timing of reproduction in response to subtle changes in food quality caused by seasonal, but annually variable, changes in water temperature, then we would expect a correlation between the timing of reproduction and sea surface temperature across years. Data from seven years of study on this population showed a highly significant relationship between sea surface temperature and the median copulation date; the warmer the water in December, the earlier the breeding season began. Without a direct test, it is difficult to unravel the correlation between sea surface temperature and food availability to determine which of these two alternate hypotheses is more likely. We do know, however, that the timing of reproduction does not appear to coincide with the lowest low tides of the 
month of copulation when the most algae should be exposed, as has been previously suggested (Boersma 1983). Similarly, the idea that the breeding cycle may be adapted to avoid the cool and dry garua season because the eggs may become too cold or dry to hatch (Carpenter 1966) also seems unlikely because the garua season is highly unpredictable from year to year and begins many months after breeding occurs on Santa Fé.

Since ambient temperature and seasonal fluctuations in thermoperiod are thought to help modulate reptile circadian cycles via melatonin release from the pineal gland (Underwood and Calaban 1987, Underwood 1992, Foà et al. 1994, Tosini et al. 2001), it is conceivable that direct temperature cues could be used to regulate reproductive timing. However, it is unlikely that marine iguanas cue directly on sea surface temperature, given the high frequency and intensity of El Niño events in the Galápagos Islands (every $3.8 \mathrm{yr}$; Quinn et al. 1987, Laurie 1989) that cause large within and among year variation in sea surface temperatures (Laurie 1989). Even in years with relatively weak El Niño events, the sea surface temperature anomaly, or the degree of variation from the mean monthly sea surface temperature, can be quite large and indirectly affect marine iguana reproductive success (Laurie 1989) and survival (Wikelski et al. 2002). In strong El Niño years, when the sea surface temperatures become warmer earlier in the year, we would expect iguanas to breed earlier if sea surface temperature were the only cue they use. Although significantly fewer individuals breed during El Niño years (Laurie 1990a; M. Wikelski, unpublished data), those that do continue to breed around the middle of December on Santa Fé. During the two strong El Niño years from which we were able to obtain copulation data, breeding was not related to December sea surface temperature.

In contrast to the unreliable and potentially maladaptive cue of sea surface temperature, food quality would be a more reliable cue because it directly represents a resource that iguanas need to breed: energy. Food availability can directly affect reproductive output in Galápagos lava lizards (Jordon and Snell 2002), and is known to limit the frequency of reproduction across years in many species of reptiles (Ballinger 1977, Bull and Shine 1979). In marine iguanas, most females who breed, and males who breed with large a number of females, will often forgo reproduction the following year to recover breeding condition (Laurie 1989), suggesting that not only is breeding extremely costly in this species, but that food availability can directly influence the decision to breed. Similarly, food availability could also influence the decision of when to breed. Many species of birds are known to delay breeding until they have stored enough energy (Perrins 1970), and supplemental food given prior to breeding can actually move up the clutch initiation date (Meijer and Langer 1995, Kelly and Van Horne 1997, Scheuerlein and Gwinner 2002). Many reptiles may also delay breeding until necessary food and water is available (Congdon 1989). We know from studies of body size in marine iguanas that they are severely energy limited (Wikelski et al. 1997) and that breeding is energetically demanding (Wikelski et al. 2001, M. Wikelski, K. Nelson, M. Vitousek, and A. Woakes, unpublished data). Thus, it is not surprising that marine iguanas would respond more readily to changes in carbon content (i.e., energy) than nitrogen content during the breeding season when food abundance is high. Moreover, evidence from other algae grazers like marine arthropods suggests that many key breeding life history parameters are strongly affected by algal quality, but not quantity (Hemmi and Jormalainen 2002).

\section{The evolution of marine iguana breeding life history}

Most reptiles, including many iguanines such as green iguanas and Galápagos land iguanas, are capital breeders and more sensitive to food availability after breeding, which can directly impact offspring survival (Bonnet et al. 1998). Food availability prior to breeding is not overly critical for these iguanines because they are able to accumulate and store nutrient reserves in their tails for many months prior to breeding (Burghardt and Rand 1982, van Marken Lichtenbelt 1993). Rather, food may be more critical for hatchlings, since hatching occurs at the onset of the rains when the soil is easy to dig through and new leaves are available as food for the young iguanas (Rand and Greene 1982, Snell and Tracy 1985, Bock and Rand 1989, van Marken Lichtenbelt and Albers 1993).

In contrast, marine iguanas are more likely to be income breeders and more sensitive to food availability prior to breeding, which can directly affect (1) a female's ability to conceive, or (2) indirectly affect offspring survival depending on how the female proportions nutrients. Despite the fact that some individuals may forgo breeding in successive years to recoup breeding condition (Laurie 1989), food availability immediately preceding breeding is likely to be critical given the high (compared to other iguanines) daily energy expenditure during foraging (Wikelski and Trillmich 1994, Drent et al. 1999) and breeding (Wikelski et al. 2001). Moreover, females may indirectly influence offspring survival by how they provision yolk during vitellogenesis. In many species of reptiles, including other iguanas, posthatching yolk (energy stores absorbed into the body from the egg yolk at the time of hatching; Troyer 1983, 1987) can affect hatchling quality (Congdon 1989) through enhancement of growth rates and an increased energy supply for activity (Troyer 1983, 1987). In marine iguanas, larger (weight and size) hatchlings have higher survival (Laurie and Brown 1990a), possibly illustrating the important fitness consequences of the maternally derived yolk. Finally, since hatchlings do not forage on algae for the first few months of life, food availability directly after hatching is not critical. The hypothesis that marine 
iguanas are income breeders and unable to store large energy reserves is supported by the fact that marine iguanas die of starvation during El Niños within 2-3 months (Laurie 1989, Laurie and Brown 1990a,b), while Galápagos land iguanas (capital breeders) survive many months or years of drought and starvation during La Niña periods (H. L. Snell and M. Wikelski, personal observations).

If energy is important for marine iguanas to withstand the rigors of breeding, but also to ensure high reproductive success through increased maternal investment in yolk, then we would expect the timing of reproduction to be regulated to maximize energy intake directly before and during breeding. As apparent income breeders, marine iguanas must, and do, take advantage of these food resources for as long as they can before they begin to decline in quality. The decision of when to breed coincides with the annual and inevitable downturn in the environment. This downturn is measured in terms of food quality (particularly energy content), rather than food quantity, suggesting that vertebrate marine grazers, like many species of invertebrate marine grazers (Hemmi and Jormalainen 2002), may rely on more subtle properties of food resources to regulate breeding life histories. Galápagos marine iguanas on the island of Santa Fé appear to have evolved synchronous and predictable breeding life histories in response to seasonal changes in food quality associated with corresponding changes in water temperature as a way to maximize energy intake immediately prior to breeding, and ultimately fitness.

\section{ACKNOWLEDGMENTS}

We thank F. Kuemmeth, K. Nelson, V. Ordonez, and D. Viemos for help with fieldwork. We acknowledge the Galápagos National Park Service, the Charles Darwin Research Station, and TAME (Transporte Aereo Militare Ecuadoriano) for enabling this work. Special thanks to W. Wickler, E. Gwinner, and the Max Planck Institute for continuous support, and C. P. Chamberlain, X. Feng, and M. Poage for help with the $\mathrm{CHN}$ analyzer and mass spectrometer. This is contribution number 602 of the Charles Darwin Foundation. We thank R. Holmes, A. S. Rand, D. I. Rubenstein, and P. Wrege for advice and comments improving previous versions of the manuscript. This work was supported by the James B. Reynolds Scholarship for Study Abroad from Dartmouth College, the Harvard Travellers Club Permanent Fund, the Explorers Club Youth Activity Fund, a Howard Hughes Medical Institute Predoctoral Fellowship in Biological Sciences, Dartmouth College, the University of Illinois at Urbana-Champaign, and Princeton University.

\section{Literature Cited}

Ballinger, R. E. 1977. Reproductive strategies: food availability as a source of proximal variation in a lizard. Ecology 59:628-634.

Black, W. A. P., and E. T. Dewar. 1949. Correlation of some of the physical and chemical properties of the sea with the chemical constitution of the algae. Journal of the Marine Biological Association of the United Kingdom 28:673699.

Bock, B. C., and A. S. Rand. 1989. Factors influencing nesting synchrony and hatching success at a green iguana nesting aggregation in Panama. Copeia 4:978-986.
Bodenheimer, F. S., and F. Sulman. 1946. The estrous cycle of microtus-guentheri-d and micro-guentheri-a and its ecological implications. Ecology 27:255-256.

Boersma, P. D. 1983. An ecological study of the Galapagos marine iguana. Pages 157-176 in R. I. Bowman, M. Berson, and A. E. Leviton, editors. Patterns of evolution in Galapagos organisms. American Association for the Advancement of Science, San Francisco, California, USA.

Bomford, M. 1987. Food and reproduction in wild house mice. II. A field experiment to examine the effect of food availability and food quality on breeding in spring. Australian Wildlife Research 14:197-206.

Bonnet, X., D. Bradshaw, and R. Shine. 1998. Capital versus income breeding: an ectothermic perspective. Oikos 83: 333-342.

Bull, J. J., and R. Shine. 1979. Iteroparous animals that skip opportunities for reproduction. American Naturalist 114: 296-303.

Bunnell, F. L. 1980. Factors controlling lambing period of Dall's sheep. Canadian Journal of Zoology 58:1027-1031.

Burghardt, G. M., and A. S. Rand. 1982. Iguanas of the world: their behavior, ecology, and conservation. Noyes Publications, Park Ridge, New Jersey, USA.

Caceres, C. W., L. S. Fuentes, and F. P. Ojeda. 1994. Optimal feeding strategy of the temperate herbivorous fish Aplodactylus punctatus: the effects of food availability on digestive and reproductive patterns. Oecologia 99:118-123.

Carpenter, C. C. 1966. The marine iguana of the Galapagos Islands, its behavior and ecology. Proceedings of the California Academy of Sciences (Series 4) 34:329-376.

Clifton, K. E. 1995. Asynchronous food availability on neighboring Caribbean coral reefs determines seasonal patterns of growth and reproduction for the herbivorous parrotfish Scarus iserti. Marine Ecology Progress Series 116: 39-46.

Congdon, J. D. 1989. Proximate and evolutionary constraints on energy relations in reptiles. Physiological Zoology 62: 356-373.

Cook, R. C., D. L. Murray, J. G. Cook, P. Zager, and S. L. Monfort. 2001. Nutritional influences on breeding dynamics in elk. Canadian Journal of Zoology 79:845-853.

Cote, S. D., and M. Festa-Bianchet. 2001. Birthdate, mass and survival in mountain goat kids: effects of maternal characteristics and forage quality. Oecologia 127:230-238.

Darwin, C. 1883. Journal of researches into the natural history and geology of the countries visited during the voyage round the world of H.M.S. Beagle. Republished edition. Appleton, New York, New York, USA.

Dawson, W. R., G. A. Bartholomew, and A. F. Bennett. 1977. A reappraisal of the aquatic specializations of the Galapagos marine iguana (Amblyrhynchus cristatus). Evolution 31:891-897.

Drent, R. H., and S. Daan. 1980. The prudent parent: energetic adjustments in avian breeding. Ardea 68:225-252.

Drent, J., W. Lichtenbelt, and M. Wikelski. 1999. Foraging mode and seasonality effects on the energetics of the marine iguana Amblyrhynchus cristatus. Functional Ecology 13: 493-499.

Duarte, C. M. 1992. Nutrient concentration of aquatic plants: patterns across species. Limnology and Oceanography 37: 882-889.

Eibl-Eibesfeldt, I. 1984. The large iguanas of the Galapagos Islands. Pages 157-173 in R. Perry, editor. Key environments: Galapagos. Pergamon Press, New York, New York, USA.

Fahrbach, E., F. Trillmich, and W. Arntz. 1991. The time sequence and magnitude of physical effects of El Niño in the eastern Pacific. Pages 8-21 in F. Trillmich and K. A. Ono, editors. Pinnipeds and El Niño. Springer-Verlag, Heidelberg, Germany. 
Feldman, G. C. 1986. Patterns of phytoplankton production around the Galapagos islands. Pages 77-106 in J. Bowman, M. Yentsch, and W. T. Peterson, editors. Lecture notes on coastal and estuarine studies. Volume 17. Tidal mixing and plankton dynamics. Springer-Verlag, Berlin, Germany.

Foà, A., G. Montefort, L. Minutini, A. Innocenti, C. Quaglieri, and M. Flamini. 1994. Seasonal changes in locomotor activity patterns in ruin lizards Podarcis sicula. Behavioral Ecology and Sociobiology 34:267-274.

Fralick, R. A., H. P. Baldwin, A. I. Neto, and E. J. Hehre. 1990. Physiological responses of Pterocladia and Gelidium (Gelidiales, Rhodophyta) from the Azores, Portugal. Hydrobiologia 204/205:479-482.

Fredriksen, S., and J. Rueness. 1989. Culture studies of Gelidium latifolium (Grev.) born et thur. (Rhodophyta) from Norway: Growth and nitrogen storage in response to varying photon flux density, temperature and nitrogen availability. Botanica Marina 32:539-546.

Hanisak, M. D. 1979. Nitrogen limitation of Codium fragile spp. tomentosoides as determined by tissue analysis. Marine Biology 50:333-337.

Hemmi, A., and V. Jormalainen. 2002. Nutrient enhancement increases performance of a marine herbivore via quality of its food alga. Ecology 83:1052-1064.

Hernandez-Guerrero, C. J., M. Casa-Valdez, S. OrtegaGarcia, and S. Hernandez-Vazquez. 2000. Effect of climatic variation on the relative abundance of the red alga Gelidium robustum in Baja California Sur, Mexico. Journal of Applied Phycology 12:177-183.

Houvenaghel, G. T. 1978. Oceanographic conditions in the Galápagos archipelago and their relationships with life on the islands. Pages 181-200 in R. Boje and P. Tomczak, editors. Upwelling ecosystems. Springer-Verlag, Berlin, Germany.

Jordon, M. A., and H. L. Snell. 2002. Life history trade-offs and phenotypic plasticity in the reproduction of Galápagos lava lizards (Microlophus delanonis). Oecologia 130:4452.

Kaehler, S., and R. Kennish. 1996. Summer and winter comparisons in the nutritional value of marine macroalgae from Hong Kong. Botanica Marina 39:11-17.

Kelly, J. F., and B. Van Horne. 1997. Effects of food supplementation on the timing of nest initiation in belted kingfishers. Ecology 78:2504-2511.

Kennish, R. 1997. Seasonal patterns of food availability: influences on the reproductive output and body condition of the herbivorous crab Grapsus albolineatus. Oecologia 109: 209-218.

Lack, D. 1947. The significance of clutch-size. Ibis 89:302352.

Lapointe, B. E., and J. H. Ryther. 1979. The effects of nitrogen and seawater flow rate on the growth and biochemical composition of Gracilaria foliifera var. angustissima in mass outdoor cultures. Botanica Marina 22:529-537.

Laurie, W. A. 1989. Effects of the 1982-83 El Niño-Southern Oscillation event on marine iguana (Amblyrhynchus cristatus, Bell, 1825) populations in the Galápagos islands. Pages 121-141 in P. Glynn, editor. Global ecological consequences of the 1982-83 El Niño-Southern Oscillation. Elsevier, New York, New York, USA.

Laurie, W. A. 1990. Population biology of marine iguanas (Amblyrhynchus cristatus). 1. Changes in fecundity related to a population crash. Journal of Animal Ecology 59:515528.

Laurie, W. A., and D. Brown. 1990a. Population biology of marine iguanas (Amblyrhynchus cristatus). 2. Changes in annual survival rates and the effects of size, sex, age and fecundity in a population crash. Journal of Animal Ecology 59:529-544.
Laurie, W. A., and D. Brown. 1990b. Population biology of marine iguanas (Amblyrhynchus cristatus). 3. Factors affecting survival. Journal of Animal Ecology 59:545-568.

Macler, B. A. 1986. Regulation of carbon flow by nitrogen and light in the red algae, Gelidium coulteri. Plant Physiology 82:136-141.

Macler, B. A. 1988. Salinity effects photosynthesis, carbon allocation, and nitrogen assimilation in the red algae, $\mathrm{Gel}$ idium coulteri. Plant Physiology 88:690-694.

Meijer, T., and U. Langer. 1995. Food availability and egglaying of captive European starlings. Condor 97:718-728.

Niell, F. X. 1976. C:N ratio in some marine macophytes and its possible ecological significance. Botanica Marina 19: 347-350.

Oliger, P., and B. Santelices. 1981. Physiological ecology studies on Chilean Gelidiales. Journal of Experimental Marine Biology and Ecology 53:65-75.

Pak, H., and J. R. V. Zanveld. 1973. The Cromwell Current on the east side of the Galapagos Islands. Journal of Geophysical Research 78:4845-7859.

Partecke, J., A. von Haeseler, and M. Wikelski. 2002. Territory establishment in lekking marine iguanas, Amblyrhynchus cristatus: support for the hotshot mechanism. Behavioral Ecology and Sociobiology 51:579-587.

Patterson, G. W. 1977. Survey of chemical components and energy considerations. Pages 271-287 in R. W. Krauss, editor. The marine plant biomass of the Pacific Northwest Coast. Oregon State University Press, Corvallis, Oregon, USA.

Perrins, C. M. 1970. The timing of birds' breeding seasons. Ibis 112:242-255.

Pianka, E. R. 1976. Natural selection of optimal reproductive tactics. American Zoologist 16:775-784.

Quinn, W. H., V. T. Neal, and S. E. Antunez de Mayolo. 1987. El Niño occurrences over the past four and a half centuries. Journal of Geophysical Research 92:14449-14461.

Rand, A. S., and H. W. Greene. 1982. Latitude and climate in the phenology of reproduction in the green iguana. Pages 142-149 in G. M. Burghardt and A. S. Rand, editors. Iguanas of the world: their behavior, ecology, and conservation. Noyes Publications, Park Ridge, New Jersey, USA.

Rico, J. M., and C. Fernandez. 1996. Seasonal nitrogen metabolism in an intertidal population of Gelidium latifolium (Gelidiaceae, Rhodophyta). European Journal of Phycology 31: $149-155$.

Romero, M. L., and M. Wikelski. 2001. Corticosterone levels predict survival probabilities of Galapagos marine iguanas during El Niño events. Proceedings of the National Academy of Sciences (USA) 98:7366-7370.

Rutberg, A. T. 1987. Adaptive hypotheses of birth synchrony in ruminants: an interspecific test. American Naturalist 130: 692-710.

Santelices, B. 1991. Production ecology of Gelidium. Hydrobiologia 221:31-44.

Scheuerlein, A., and E. Gwinner. 2002. Is food availability a circannual zeitgeber in tropical birds? A field experiment on stonechats in tropical Africa. Journal of Biological Rhythms 17:171-180.

Snell, H. L., and C. R. Tracy. 1985. Behavioral and morphological adaptations by Galapagos land iguanas (Conolophus pallidus) to water and energy requirements of eggs and neonates. American Zoologist 25:1009-1018.

Sterner, R. W., and D. O. Hessen. 1994. Algal nutrient limitation and the nutrition of aquatic herbivores. Annual Review of Ecology and Systematics 25:1-29.

Talbot, L., and M. Talbot. 1963. The wildebeest in western Masailand, East Africa. Wildlife Monographs 12:8-88.

Thorne, E. T., R. E. Dean, and W. G. Hepworth. 1976. Nutrition during gestation in relation to successful reproduction in elk. Journal of Wildlife Management 40:330-335. 
Tosini, G., C. Bertolucci, and A. Foà. 2001. The circadian system of reptiles: a multioscillatory and multiphotoreceptive system. Physiology and Behavior 72:461-471.

Trillmich, K. G. K., and F. Trillmich. 1986. Foraging strategies of the marine iguana, Amblyrhynchus cristatus. Behavioral Ecology and Sociobiology 18:259-266.

Troyer, K. 1982. Transfer of fermentive microbes between generations in a herbivorous lizard. Science 216:540-542.

Troyer, K. 1983. Posthatching yolk energy in a lizard: utilization pattern and interclutch variation. Oecologia 58: 340-344.

Troyer, K. 1987. Posthatching yolk in a lizard: internalization and contribution to growth. Journal of Herpetology 21:102106.

Underwood, H. 1992. Endogenous rhythms. Pages 229-297 in C. Gans, editor. Biology of Reptilia: hormones, brain, and behavior. Volume 18. University of Chicago Press, Chicago, Illinois, USA.

Underwood, H., and M. Calaban. 1987. Pineal melatonin rhythms in the lizard Anolis carolinensis: I. Response to light and temperature cycles. Journal of Biological Rhythms 2:179-193.

van Marken Lichtenbelt, W. D. 1993. Optimal foraging of a herbivorous lizard, the green iguana in a seasonal environment. Oecologia 95:246-256.

van Marken Lichtenbelt, W. D., and K. B. Albers. 1993. Reproductive adaptations of the green iguana on a semiarid island. Copeia 3:790-798.

Wiewandt, T. A. 1982. Evolution of nesting patterns in iguanine lizards. Pages 119-141 in G. M. Burghardt and A. S. Rand, editors. Iguanas of the world: their behavior, ecology, and conservation. Noyes Publications, Park Ridge, New Jersey, USA.

Wikelski, M., and S. Bäurle. 1996. Pre-copulatory ejaculation solves time constraints during copulations in marine iguanas. Proceedings of the Royal Society of London, Series B 263:439-444.

Wikelski, M., C. Carbone, P. A. Bednekoff, C. Choudhury, and S. Tebbich. 2001. Female choice in marine iguana leks: a wider selection of males obtained at a cost. Ethology 107: 623-638.

Wikelski, M., C. Carbone, and F. Trillmich. 1996. Lekking in marine iguanas: female grouping and male reproductive strategies. Animal Behavior 52:581-596.

Wikelski, M., V. Carrillo, and F. Trillmich. 1997. Energy limits to body size in a grazing reptile, the Galapagos marine iguana. Ecology 78:2204-2217.

Wikelski, M., B. Gall., and F. Trillmich. 1993. Ontogenetic changes in food intake and digestion rate of the herbivorous marine iguana (Amblyrhynchus cristatus, Bell). Oecologia 94:373-379.

Wikelski, M., and F. Trillmich. 1994. Foraging strategies of the Galapagos marine iguana (Amblyrhynchus cristatus): adapting behavioral rules to ontogenetic size change. Behaviour 128:255-279.

Wikelski, M., V. Wong, B. Chavalier, N. Rattenborg, and H. L. Snell. 2002. Marine iguanas die from trace oil pollution. Nature 417:607-608.

Wikelski, M., and P. H. Wrege. 2000. Niche expansion, body size, and survival in Galápagos marine iguanas. Oecologia 124:107-115.

Wingfield, J. C., T. P. Hahn, and D. Doak. 1993. Integration of environmental factors regulating transitions of physiological state, morphology and behaviour. Pages 111-122 in P. J. Sharp, editor. Avian Endocrinology. Journal of Endocrinology, Bristol, UK.

Wingfield, J. C., T. P. Hahn, R. Levin, and P. Honey. 1992. Environmental predictability and control of gonadal cycles in birds. Journal of Experimental Zoology 261:214231 . 